\section{Entre o biológico e o social. Um estudo sobre os Congressos Brasileiros de Epidemiologia, 1990-2002*}

\author{
Between biological and social \\ factors. A study of Brazilian \\ epidemiology congresses, 1990 - \\ 2002*
}

\section{Resumo}

A discussão sobre os conceitos de biológico e social na determinação do processo saúde-doença é estruturante na Saúde Coletiva no Brasil, e no campo epidemiológico. Este artigo apresenta os resultados da pesquisa qualitativa dos Anais dos Congressos Brasileiros de Epidemiologia, no período de 1990 a 2002. Tem como objetivo identificar as noções de biológico e social, neles contidos, com vistas à identificação dos pressupostos teóricos que os norteiam. Os resultados demonstraram que o conceito de social refere-se, principalmente, à esfera do 'societário', ancorado na dissociação disciplinar das ciências naturais e sociais. O biológico é atribuído à esfera individual e clínica do processo saúde-doença, raramente à esfera do coletivo, bem como um conceito portador de objetividade. Entre o biológico e o social, o ambiente aparece como categoria autônoma; o biológico aparece ainda, porém de forma embrionária, como complexo, histórico e intrinsecamente social. A análise dos resultados apontou para uma necessária redefinição de marcos teóricos que possibilitem o avanço dos conhecimentos na área e, conseqüentemente, das práticas em saúde que a Epidemiologia subsidia. O projeto de pesquisa passou pelo Comitê de Ética em Pesquisa do Instituto de Saúde SESSP, tendo sido aprovado.

Palavras-chave: Epidemiologia. Biológico. Social. Ciências sociais. Ciências naturais. Saúde coletiva.

\section{Aurea Maria Zöllner lanni}

Instituto de Saúde da Secretaria de Estado da Saúde de São Paulo, Faculdade de Ciências Médicas da Santa Casa de São Paulo

\footnotetext{
* Este trabalho corresponde à parte da pesquisa de Doutorado, defendido junto ao Programa de Pós-Graduação em Ciência Ambiental da Universidade de São Paulo, 2004.

* This paper corresponds to part of a PhD research of Environmental Science Pos-Graduation Program of the São Paulo University. 2004.

Correspondência: Áurea Maria Zöllner lanni. Rua Santo Antonio, 590, $5^{\circ}$ andar, CEP 01314-000. Bela Vista, São Paulo, SP.E-mail: aureanni@isaude.sp.gov.br
} 


\section{Abstract}

The discussion on the concepts of biological and social factors in the determination of the health-illness process is a basic theme in Public Health in Brazil, and in the epidemiological field. This article presents the results of a qualitative research on the records of Brazilian Epidemiology Congresses in the period between 1990 and 2002. Its objective is to identify the notions of biological and social factors, seeking to recognize the theoretical assumptions underlying them. Results demonstrated that the concept of social factor is mentioned mainly in the sphere of 'societary', anchored in the dissociation between natural and social sciences. The biological factor is associated with the individual and clinical sphere of the health-illness process, seldom attributed to the sphere of collective, and it is perceived as the bearer of the concept of objectivity. In the biological-social relation, the environment appears as an independent category; the biological factor also appears, in an incipient form, as a complex, historical and intrinsically social concept. The analysis pointed toward the need for a theoretical redefinition that could enable the advancement of knowledge in the area, and, consequently, of health practices based on Epidemiology. The research project has been through the Etical Research Committee of the Instituto de Saúde SESSP and was aproved.

Keywords: Epidemiology. Biological. Social. Social sciences. Natural sciences. Public health.

\section{Introdução}

Disciplina constituinte das escolas médicas e de saúde em geral, a Epidemiologia não escapa à hegemonia do modelo biomédico ${ }^{1,2}$. No Brasil, a partir da década de 1970, a Epidemiologia, preocupada com os determinantes sociais da doença, vai postular uma crítica sistemática a este paradigma, na perspectiva da sua superação. Neste contexto, ganha expressão a discussão sobre os conceitos de biológico e social e suas inter-relações, tendo em vista o processo de saúde e adoecimento nas populações. Marsiglia \& Spinelli ${ }^{3}$, discutindo as ciências sociais e o ensino em saúde, mencionam a forte entonação biomédica deste e propõem o desafio de enfrentar essa questão na busca das mediações entre o biológico e o social. Stotz ${ }^{4}$ confirma esse impasse quando diz que "foi em torno da complexa relação, proposta na tradição científica ocidental, entre objetos distintos do ponto de vista epistemológico - o biológico e o social que os desafios foram postos (p. 278)" ${ }^{\prime 4} \mathrm{Na}$ perspectiva crítica a esta concepção hegemônica, uma vertente da Epidemiologia brasileira vai se reposicionar teoricamente, resultando daí um arcabouço conceitual que influenciará todo o campo; um pensamento epidemiológico social, crítico que irá se desdobrar e desenvolver nas décadas seguintes.

A introdução da concepção históricoestrutural na saúde ${ }^{5,6}$ marca a incorporação de categorias que modificaram os marcos analíticos da Epidemiologia. As principais mudanças foram a substituição da noção de causalidade biológica pelo conceito de determinação social, e a formulação do conceito de processo saúde-doença, que propõe a superação dessa polaridade tendo em vista a complexidade desses estados. Com o conceito de determinação social, incorporou-se o princípio da historicidade - política, econômica e cultural -, necessário a qualquer disciplina que se proponha a trabalhar com seres humanos em sociedades; permitiu, tam- 
bém, superar o pensamento linear causal, de bases funcionalistas*, abrindo espaço para a compreensão dos contextos complexos e contraditórios.

Se, por um lado, no campo disciplinar da biologia, a sua vertente molecular fazia renascer a ideologia da aptidão individual sobre o social e o cultural, influenciando largamente as ciências da saúde, por outro, tratava-se, segundo Barreto ${ }^{8}$, de um momento de "profunda crise econômica e social associada à intensa repressão política e ideológica [em que] renasce o interesse pela determinação social das doenças (p. 24)" ${ }^{8}$. Esse também é o período de florescimento e auge da epidemiologia clínica, que se ajusta, perfeitamente, à concepção biomédica.

O campo da Saúde Coletiva estruturará suas bases, portanto, na crítica ao biologicismo, funcionalista e desvinculado do social. Esse movimento encontrou expressão política no que veio a se denominar de Reforma Sanitária Brasileira ${ }^{9}$. Neste contexto, em 1979, constituiu-se a Associação Brasileira de Pós-Graduação em Saúde Coletiva, a ABRASCO, congregando os profissionais da docência, da pesquisa e da prestação de serviços, sujeitos e instituições bastante diferenciados entre si, muitas vezes com interesses conflitantes e até contraditórios $^{10}$, um campo $^{11}$ heterogêneo. A Epidemiologia participa desse movimento construindo um marco teórico social, crítico, próprio ${ }^{1,12-14}$. É a esse universo, a esse sujeito coletivo, a esse ator social que o presente trabalho se reporta.

\section{O Campo da Determinação}

Pereira $^{15}$, Loureiro ${ }^{16}$ e Almeida Filho ${ }^{17}$ nos servirão de referência desse marco teórico por representarem, exemplarmente, a discussão sobre a determinação social do processo saúde-doença. Suas produções datam do período da gênese do campo, que tem como marco o I Congresso Brasileiro de Epidemiologia que ocorre em 1990.
É importante mencionar a obra de Ayres $^{18,19}$, que transcorre em linha teórica diferenciada. Publicada, entretanto, em meados dos anos 90, ela será incorporada no decurso do período em estudo.

No que se refere a Pereira, Loureiro e Almeida Filho, parece haver uma concordância quanto ao fato de que o objeto da epidemiologia é caudatário do marco biomédico. Almeida Filho coloca-o claramente ao identificá-lo ao "objeto-semblante” da clínica, derivado de uma ontologia de entidades mórbidas: "o objeto-modelo da epidemiologia constitui-se nas relações de ocorrência subsidiárias ao objeto clínico (p. 214)"17. O mesmo significado aparece no texto de Pereira, que identifica as raízes da Medicina Social na Medicina 'clínica', que "vai deixando de ser quase que apenas o conhecimento (biológico principalmente) das doenças e dos meios de curá-la e/ou a ciência do corpo biológico, normal e patológico (p. 76)"15, dirigindo-se ao processo saúde-doença histórico-social. Para esses autores parece não haver dúvidas sobre a origem médico-clínica do objeto epidemiológico.

A construção do objeto epidemiológico, proposta pelos marcos do movimento sanitário brasileiro, vai criticar, portanto, esse objeto de matriz biomédica, “clínica”, quanto à sua aparente limitação, circunscrição. Segundo os críticos, essa matriz recai sobre o excesso de biológico e a ausência do social. Na sua critica, o biológico emerge tal qual a clínica o compreende e manipula: micro, pois está relacionado aos agentes etiológicos e/ou fatores causais em oposição aos contextos mais gerais, sociais e determinantes do processo saúde-doença; e funcional, porque está relacionado à noção de normalidade que caracterizaria o indivíduo são. Ao se subsidiar no "objetosemblante" da clínica, o "objeto-modelo"17 da epidemiologia ficaria extremamente engessado num determinado território das ciências biológicas e da biomedicina. Um território implacavelmente marcado por

* Expressa a idéia de que tudo o que existe numa sociedade contribui para manter o sistema social em operação. Confunde-se com uma teoria do equilíbrio social, evitando se posicionar perante as tensões, conflitos e contradições das sociedades humanas.? 
uma biologia funcional e microscópica, classificatória e fragmentada.

A guinada em direção ao social - às ciências humanas e às sociais, mais especificamente -, com ênfase na corrente do materialismo dialético, descortinou, para os críticos da biomedicina, novos contornos do objeto epidemiológico, abrindo perspectivas de incorporação da complexidade da realidade e da determinante histórica dos processos de saúde-doença em populações concretas. É nessa perspectiva que Pereira vai afirmar que o objeto da Medicina Social "não é representado por corpos biológicos, mas por corpos sociais (p. 77)"15. Instaura-se o marco do social, distinguindo-se, numa relação de negação, do marco biológico.

O social que emerge com força maior nessa proposta, tomando-se o texto de Loureiro ${ }^{16}$, é um social essencialmente político, socioeconômico: "O perfil de mortalidade é dependente do desenvolvimento econômico. (...) A raiz da desigualdade está no modo de produção. (...) A doença tem a sua determinação na estrutura social, política e econômica. (...) A reprodução social determina ou condiciona o perfil de morbidade" [5]. Até mesmo a Antropologia, antiga colaboradora das práticas médicas e de saúde pública ${ }^{20}$, foi sutilmente destronada, sendo reabilitada somente em princípios da década de $1980^{21}$.

O social que se instaura na Epidemiologia é, nesse sentido e principalmente, aquele relativo às esferas da economia - sua estrutura, modo de produção e potencial de desenvolvimento -, da política o aparelho de Estado e as políticas públicas estatais - e da sociologia - as condições de vida da população e a reprodução das condições de classe ${ }^{21}$. Reconhecendo os limites de uma determinada concepção de biológico, intrínseca ao objeto da biomedicina, a Epidemiologia vai se dirigir para os aspectos sociais dos fenômenos em saúde-doença.

Qual é, então, a crítica ao biológico que a Epidemiologia faz? De que social fala essa Epidemiologia?
O presente trabalho partiu da hipótese de que a crítica social ao referencial biomédico manteve-se refém dos marcos biologistas. Ou seja, a crítica social não se orientou por uma (re)visão ou rediscussão da noção de biológico que a biomedicina construiu; refutou esse biológico - que é referido como o "apenas biológico", o "menos rico em propriedades" -, incorporando os fatores sociais. O conceito de biológico é mantido intocado quanto à sua construção epistemológica, o que vai marcar o debate sobre o biológico e o social que se irá desenvolver na Saúde Coletiva, no Brasil, e com ela na Epidemiologia. A Epidemiologia avança extraordinariamente na incorporação dos determinantes sociais, porém sem rediscutir, epistemologicamente, o conceito de biológico, mantendo-se, em certa medida, refém do objeto biomédico que critica $^{2,10}$.

\section{A pesquisa: metodologia e procedimentos}

Os Congressos Brasileiros de Epidemiologia promovidos pela ABRASCO, constituem evento nacional e representam o pensamento epidemiológico recente no Brasil. Seus ANAIS são um registro histórico do evento em si e das práticas e reflexões dos sujeitos envolvidos. Expressam os interesses coletivos e específicos que unem e distinguem os profissionais do campo, sendo, por isso, considerados documen$\operatorname{tos}^{22}$ - não apenas como aquele que "fala por si”, como pretensa garantia de objetividade, descontextualizada, a-histórica, excluindo a intencionalidade contida no discurso, mas, sobretudo, como produto social de sujeitos históricos ${ }^{23,24}$. Constituíram, por isso, o universo de análise. $\mathrm{O}$ conjunto da produção assumiu sua significação como "ponto de partida" e "ponto de chegada" do trabalho de pesquisa ${ }^{25}$, pois muitos dos textos constituem, simultaneamente, subsídio e objeto de análise.

A análise dos Anais foi feita em duas variantes: temática e estrutural. A análise temática identifica e agrupa as categorias e 
os conceitos operatórios mais freqüentes, no caso o biológico e o social. A análise estrutural, de conteúdo, permite extrair os nexos e as relações entre esses conceitos, relacionando as estruturas semânticas (significantes) com as estruturas sociológicas (significados), articulando, desta forma, o conteúdo dos textos com os fatores que determinam ou condicionam suas características, suas aplicações, contribuindo para que se desvende o sentido estruturador do pensamento coletivo ${ }^{26,27}$. É bastante adequada também por possibilitar o trabalho com textos muito diferentes entre si (estudos de casos, textos analíticos ou teórico-conceituais, relatos de oficinas de trabalho, conferências, moções, etc.). A categoria biológico se constituiu num "traçador" que orientou a garimpagem dos/nos textos, estabelecendo-se, a partir dela, a interlocução com a categoria social.

A ABRASCO realizou, no período de 1990 a 2002, cinco Congressos Brasileiros de Epidemiologia: o primeiro, em Campinas, 1990, com o tema "Epidemiologia e Desigualdade Social: os Desafios do Final do Século”; o segundo, em Belo Horizonte, 1992, com o tema "Qualidade de Vida: Compromisso Histórico da Epidemiologia”; o terceiro, em Salvador, 1995, com o tema "A Epidemiologia na Busca da Eqüidade em Saúde"; o quarto, no Rio de Janeiro, 1998, com o tema "Epidemiologia em Perspectiva: Novos Tempos, Pessoas e Lugares”, o quinto, em Curitiba, 2002, com o tema "A Epidemiologia na Promoção da Saúde”. Destes, apenas o quarto Congresso não têm Anais publicados.

A seleção dos textos analisados obedeceu aos seguintes critérios: retiraram-se aqueles de autoria dos convidados estrangeiros, já que a pesquisa é sobre o pensamento brasileiro; excluíram-se os textos que sequer referiam os conceitos objeto da pesquisa ou o faziam de forma extremamente tangencial (os estudos de epidemiologia de serviços, mais especificamente planejamento e gestão, os estritamente metodológicos, ou de sistemas de informação, além das análises de conjuntura ou das políticas públicas em geral). Alguns textos reproduziam abordagens similares, o que fez com que só um deles fosse considerado. De um total de 130 textos lidos, compilados nos Anais, resultaram 48 textos selecionados que constituíram o universo da análise (relação abaixo). Os trechos identificados por números e entre colchetes, no presente artigo, ilustram o material analisado.

O conjunto das idéias, representações e conceituações encontradas, conformaram, ao final do processo de análise, a noção que a Epidemiologia Social tem sobre o biológico e o social. Noção porque, além dos conceitos e categorias explicitados, trabalhou-se com as formas "ocultas", subsumidas e subentendidas sobre o tema em questão ${ }^{28}$.

\section{Relação dos Textos Analisados}

\section{CONGRESSO BRASILEIRO DE EPIDEMIOLOGIA (1990, Campinas)}

Tema: "Epidemiologia e Desigualdade Social: os Desafios do final do Século”

[1] Oficina: "Ensino da Epidemiologia nos Cursos de Graduação, Residência e Especialização, Mestrado e Doutorado" (p. 25-29)

[2] Oficina: "Sistemas de Informação em Saúde: como usar fontes de dados para a geração de Indicadores Epidemiológicos" (p. 30-32)

[3] Oficina: "Vigilância Epidemiológica Reformulação do Sistema face à Municipalização dos Serviços de Saúde" (p. 33-36)

[4] Oficina: "Análise dos Programas de Controle de Doenças - Avaliação de suas Estratégias de Integração ao SUS" (p. 37-43)

[5] Conferência: LOUREIRO, Sebastião. "Brasil, Desigualdade Social, Doença e Morte” (p 63-80)

[6] Conferência: RODRIGUES DA SILVA, Guilherme. “Avaliação e Perspectivas da Epidemiologia no Brasil” (p. 108-139) 
[7] Mesa Redonda: LAURENTI, Rui. “Transição Demográfica e Transição Epide-miológica” (p. 143-165)

[8] Mesa Redonda: MOTA, Eduardo. "Avanços Metodológicos na Epidemiologia” (p. 198-200)

[9] Mesa Redonda: BARATA, Rita Barradas. "Epidemiologia: Teoria e Método" (p. 216-223)

[10] Mesa Redonda: FIORI, José Luis. "Caos e Crise: a Saúde no fim do Século" (p. 234-240)

[11] Mesa Redonda: GUIMARÃES, Reinaldo. "Nova Perspectivas Temáticas para a Epidemiologia” (p. 241-247)

[12] Mesa Redonda: GOLDBAUM, Moisés. "Novas Perspectivas Temáticas para a Epidemiologia" (p. 247-253)

[13] Mesa Redonda: VICTORA, César G.; FACCHINI, Luiz Augusto; BARROS, Fernando C.; LOMBARDI, Cíntia. "Pobreza e Saúde: como medir nível Sócio-Econômico em Estudos Epidemiológicos de Saúde Infantil?” (p. 302315)

[14] Mesa Redonda: POSSAS, Cristina de A. "Perspectivas para a Ciência Epidemiológica numa Abordagem Interdisciplinar" (p. 316-329)

[15] Mesa Redonda: ALMEIDA FILHO, Naomar. "Paradigmas em Epidemiologia” (p. 329-346)

[16] Mesa Redonda: MENDES GONÇALVES, Ricardo Bruno. “Contribuição à Discussão sobre as Relações entre Teoria, Objeto e Método em Epidemiologia” (p. 346-361)

[17] Painel: "Proposta do Centro Nacional de Epidemiologia” (p. 369-376)

\section{CONGRESSO BRASILEIRO DE EPIDEMIOLOGIA. (Belo Horizonte, 1992)}

Tema: "Qualidade de Vida: Compromisso Histórico da Epidemiologia”

[18] RUFFINO NETTO, Antonio. “Qualidade de Vida: Compromisso Histórico da Epidemiologia” (p. 11-18)
[19] VÍCTORA, César G. e BARROS, Fernando C. "Repensando a Associação entre Indicadores de Saúde e Qualidade de Vida” (p. 19-23)

[20] MINAYO, Maria Cecília S. "Quantitativo e Qualitativo em Indicadores de Saúde: Revendo Conceitos” (p. 25-33)

[21] DIAS, José Carlos P. “Doença de Chagas no Brasil: Situação Atual e Perspectivas" (p. 37-43)

[22] LIBEL, Mauro. “Cólera: Situação e Tendências” (p. 53-59)

[23] MENDONÇA, Gulnar A. e S. "Câncer no Brasil: um Risco Crescente” (p. 6377)

[24] BARRETO, Maurício.; ALVES, Paulo C. "O Coletivo Versus o Individual na Epidemiologia: Contradição ou Síntese?" (p. 129-136)

[25] RODRIGUES DA SILVA, Guilherme. “A Epidemiologia na Organização dos Serviços de Saúde” (p. 183-187)

[26] BUSS, Paulo M. "Desenvolvimento, Ambiente e Saúde” (p. 227-239)

[27] Oficina: CZRESNIA, Dina; BARISON, Elena de M.; AYRES, José Ricardo de M.; CASTIEL, Luis D.; FACCHINI, Luiz A.; OLIVEIRA, Luiz R.; MENDES GONÇALVES, Ricardo B.; NEHMY, Rosa M. Q. "Fundamentos Conceituais em Epidemiologia” (p. 273-275)

[28] Oficina: MENDONÇA, Elisabeth F.; COSENZA, Gilvânia W.; CARVALHO, Diana M. de; GUTIERREZ, Eliana B.; SEVALHO, Gil; CARMO, José C. do; RIBEIRO, José Geraldo L.; TOLEDO, Luciano; COSTA, Márcia C.; ALFRADIQUE, Maria Elmira M.; TEIXEIRA, Maria da Glória; CARVALHO, Marília S.; LIBEL, Mauro; OLIVEIRA, Olívia L. de; LADEIRA, Roberto L. "Repensando a Vigilância Epidemiológica” (p. 277-280)

\section{CONGRESSO BRASILEIRO DE EPIDEMIOLOGIA. (Salvador, 1995)}

Tema: "A Epidemiologia na busca da eqüidade em saúde” 
[29] "Introdução". In: Barata, R. B.; Barreto, M.L; Almeida Filho, N.; Veras, R. P. (Orgs).1997. Eqüidade e Saúde: Contribuições da Epidemiologia. Série Epidemiológica 1. Editora Fiocruz/ ABRASCO. Rio de Janeiro. (p. 11-19)

[30] GOLDBAUM, Moisés. “A Epidemiologia em Busca da Eqüidade em Saúde”. In: In: Barata, R. B.; Barreto, M.L; Almeida Filho, N.; Veras, R. P. (Orgs).1997. Eqüidade e Saúde: Contribuições da Epidemiologia. Série Epidemiológica 1. Editora Fiocruz/ ABRASCO. Rio de Janeiro. (p. 63-80)

[31] BARROS, Marilisa B. de A.. “Epidemiologia e Superação das Iniqüidades em Saúde”. In: Barata, R. B.; Barreto, M.L; Almeida Filho, N.; Veras, R. P. (Orgs).1997. Eqüidade e Saúde: Contribuições da Epidemiologia. Série Epide-miológica 1. Editora Fiocruz/ ABRASCO. Rio de Janeiro. (p. 161-176)

[32] AKERMAN, Marco. “Diferenciais Intra-Urbanos em São Paulo: Estudo de Caso de Macrolocalização de Problemas de Saúde”. In: Barata, R. B.; Barreto, M.L; Almeida Filho, N.; Veras, R. P. (Orgs).1997. Eqüidade e Saúde: Contribuições da Epidemiologia. Série Epidemiológica 1. Editora Fiocruz/ ABRASCO. Rio de Janeiro. (p. 177-186)

[33] LOPES, Antonio A. "Significado de Raça em Pesquisas Médicas e Epidemiológicas”. In: Barata, R. B.; Barreto, M.L; Almeida Filho, N.; Veras, R. P. (Orgs).1997. Eqüidade e Saúde: Contribuições da Epidemiologia. Série Epide-miológica 1. Editora Fiocruz/ ABRASCO. Rio de Janeiro. (p. 245-251)

[34] “Apresentação”. In: Almeida Filho, N.; Barreto, M.L; Veras, R. P; Barata, R. B. (Orgs).1998. Teoria Epidemiológica Hoje. Fundamentos, Interfaces, e Tendências. Série Epidemiológica 2. Editora Fiocruz/ABRASCO. Rio de Janeiro. 1998 (p. 9-20)

[35] CZERESNIA, Dina \& ALBUQUERQUE, Maria de Fátima M. de. "Limites da Inferência Causal”. In: Almeida Filho, N.; Barreto, M.L; Veras, R. P; Barata,
R. B. (Orgs).1998. Teoria Epidemiológica Hoje. Fundamentos, Interfaces, e Tendências. Série Epidemiológica 2. Editora Fiocruz/ ABRASCO. Rio de Janeiro. (p. 63-78)

[36] SCHRAMM, Fermin R.. "Epidemiologia, Tecnociência e Bioética”. In: Almeida Filho, N.; Barreto, M.L; Veras, R. P; Barata, R. B. (Orgs).1998. Teoria Epidemiológica Hoje. Fundamentos, Interfaces, e Tendências. Série Epidemiológica 2. Editora Fiocruz/ ABRASCO. Rio de Janeiro. 1998 (p. 149-164)

[37] MARQUES, Marília M.. "A Epidemiologia e a Biotecnologia”. In: Almeida Filho, N.; Barreto, M.L; Veras, R. P; Barata, R. B. (Orgs).1998. Teoria Epidemiológica Hoje. Fundamentos, Interfaces, e Tendências. Série Epidemiológica 2. Editora Fiocruz/ ABRASCO. Rio de Janeiro. (p. 165-184)

[38] CASTIEL, Luis D.. "Metáforas para uma Epidemiologia Mestiça”. In: Almeida Filho, N.; Barreto, M.L; Veras, R. P; Barata, R. B. (Orgs).1998. Teoria Epidemiológica Hoje. Fundamentos, Interfaces, e Tendências. Série Epidemiológica 2. Editora Fiocruz/ ABRASCO. Rio de Janeiro. (p. 225-255)

[39] ALMEIDA, Renan M. V. R. \& INFANTOSI, Antonio F. C.. "Avaliação de Tecnologia em Saúde: uma Metodologia para Países em Desenvolvimento". In: Barreto, M.L; Almeida Filho, N.; Veras, R. P.; Barata, R. B. (Orgs).1998. Epidemiologia, Serviços e Tecnologias em Saúde. Série Epidemiológica 3. Editora Fiocruz/ ABRASCO. Rio de Janeiro. (p. 25-29)

[40] CARMO, Eduardo H.. "Câncer Ocupacional nos Países em Desenvolvimento". In: Barreto, M.L; Almeida Filho, N.; Veras, R. P.; Barata, R. B. (Orgs).1998. Epidemiologia, Serviços e Tecnologias em Saúde. Série Epidemiológica 3. Editora Fiocruz/ ABRASCO. Rio de Janeiro. (p. 117-123)

[41] “Apresentação”. In: Veras, R. P.; Barreto, M.L; Almeida Filho, N.; Ba- 
rata, R. B. (Orgs).1998. Epidemiologia. Contextos e Pluralidades. Série Epidemiológica 4. Editora Fiocruz/ ABRASCO. Rio de Janeiro. (p. 9-12)

[42] STRUCHINER, Cláudio J.; HALLORAN, Robert C. B. \& MASSAD, Eduardo. "Epidemiologia, Estatística, Filosofia e Matemática”. In: Veras, R. P.; Barreto, M.L; Almeida Filho, N.; Barata, R. B. (Orgs).1998. Epidemiologia. Contextos e Pluralidades. Série Epidemiológica 4. Editora Fiocruz/ ABRASCO. Rio de Janeiro. (p. 13-18)

[43] CARVALHEIRO, José da R.. “Epidemiologia da AIDS: Garimpando novos Paradigmas". In: Veras, R. P.; Barreto, M.L; Almeida Filho, N.; Barata, R. B. (Orgs).1998. Epidemiologia. Contextos e Pluralidades. Série Epidemiológica 4. Editora Fiocruz/ ABRASCO. Rio de Janeiro. (p. 19-27)

[44] SABINO, Ester C.. "Subtipos de HIV-1 no Brasil”. In: Veras, R. P.; Barreto, M.L; Almeida Filho, N.; Barata, R. B. (Orgs).1998. Epidemiologia. Contextos e Pluralidades. Série Epidemiológica 4. Editora Fiocruz/ ABRASCO. Rio de Janeiro. (p. 29-34)

[45] SPINK, Mary J. P.. "Proteção Vacinal e Pensamento Mágico: a Controvérsia da Vacina na Perspectiva Psicossocial”. In: Veras, R. P.; Barreto, M.L; Almeida Filho, N.; Barata, R. B. (Orgs).1998. Epidemiologia. Contextos e Plura-lidades. Série Epidemiológica 4. Editora Fiocruz/ ABRASCO. Rio de Janeiro. (p. 45-50)

[46] CÂMARA, Volney de M.. "Vigilância e Meio Ambiente: Aspectos Conceituais e Metodológicos para Áreas de Mineração de Ouro". In: Veras, R. P.; Barreto, M.L; Almeida Filho, N.; Barata, R. B. (Orgs).1998. Epidemiologia. Contextos e Pluralidades. Série Epidemiológica 4. Editora Fiocruz/ ABRASCO. Rio de Janeiro. (p. 67-78)

[47] HOSSNE, William S.. "Epide-miologia, Desenvolvimento Tecno-lógico e Ética”. In: Veras, R. P.; Barreto, M.L; Almeida Filho, N.; Barata, R. B.
(Orgs).1998. Epidemiologia. Contextos e Pluralidades. Série Epidemiológica 4. Editora Fiocruz/ABRASCO. Rio de Janeiro. (p. 147-166)

\section{CONGRESSO BRASILEIRO DE EPIDEMIOLOGIA. (Curitiba, 2002)}

Tema: "A Epidemiologia na Promoção da Saúde"

[48] BARRETO, Maurício L.. 2002. "Papel da Epidemiologia no Desenvolvimento do Sistema Único de Saúde no Brasil: histórico, fundamentos e perspectivas”. In: Revista Brasileira de Epidemiologia. Vol. 5, Suplemento 1. Novembro. São Paulo. (p. 4-17)

\section{Resultados}

A tensão biológico/social não está desvinculada de outras questões conceituais, teóricas e mesmo epistemológicas em pauta na Epidemiologia ${ }^{29}$; a causalidade ou determinação do processo saúdedoença, a linearidade e/ou fragmentação da explicação epidemiológica, o conceito de risco, a tensão quantitativo/qualitativo etc. Essas categorias e seus usos não estão, portanto, desvinculadas de teorias e métodos que permeiam o campo da Saúde. Sendo assim, o recorte proposto para a pesquisa teve o objetivo de, através desses conceitos, discutir os marcos teóricos mais gerais do pensamento epidemiológico. O biológico e o social emergiram, nos textos analisados, de forma explícita ou implícita; algumas vezes claramente definidos como conceitos, outras vezes evidenciados por meio das narrativas. Apareceram, ainda, de forma contraditória nos textos e entre textos. Considerou-se o material, como um todo, expressão do pensamento epidemiológico no período.

Há dois tipos de trabalhos: os estudos das práticas, fenômenos ou eventos epidemiológicos concretos e os textos teóricoconceituais. Os estudos empíricos constituem a esfera na qual a Epidemiologia pa- 
rece articular melhor o social e o biológico em sua complexidade, totalidade, interação: "Serão problemáticas as situações já apontadas onde prevalecem espécies ubiqüistas e disseminadas no meio ambiente, especialmente no Nordeste brasileiro e nas regiões mais pobres do País. Levese ainda em conta, nesta perspectiva, as tendências de urbanização de populações e as profundas mudanças sociais, trabalhistas e ecológicas da zona rural que vêm se processando nas últimas décadas, com enormes repercussões na flora e na fauna. Trata-se do esvaziamento da população rural, do assentamento de agroempresas mecanizadas, dos câmbios de cobertura vegetal através de projetos agropastoris intensivos e extensivos, da implantação de hidrelétricas e reflorestamentos, do emprego extensivo de defensivos agrícolas no meio ambiente etc., tudo isso diminuindo a fauna triatomínica natural e concentrando remanescentes em microespaços ainda preservados" [21]. O mesmo acontece nos textos em que se discutem as práticas epidemiológicas, quando da proposição ou discussão de estratégias de enfrentamento de alguma epidemia e/ou endemia ou sobre a organização dos serviços: “(...) a atual organização social do espaço nas áreas metropolitanas inviabiliza a implementação das atividades de controle (da febre amarela e do dengue) nos seus moldes tradicionais. $O$ crescimento das favelas, a persistência de áreas não utilizadas, que são reserva de mercado para a especulação imobiliária, o comércio clandestino de sucata e os depósitos de lixo a céu aberto criam as condições para a reprodução do vetor, enquanto a violência difusa e o crime organizado dificultam o acesso à área de transmissão potencial, ou efetiva. (...) A prevenção da febre amarela e do dengue hemorrágico são objetivos que só podem ser atingidos através de programas coordenados, que ultrapassem limites de unidades administrativas e que hoje, necessitam de métodos alternativos àqueles tradicionalmente utilizados, que pressupunham ser possível o controle sem a parti- cipação da população e das instituições locais” [4].

Nos textos conceituais ou teóricos o uso das categorias assume conotação totalmente diferente. Aqui aparecem mais evidentemente os paradoxos e/ou contradições, o que induz pensar que o tratamento dado a essas categorias no plano teórico-conceitual revela um certo divórcio entre as ciências sociais e naturais presente no campo da saúde: "O ensino e a pesquisa em Epidemiologia deveriam retomar o pensamento genérico de entender a doença ultrapassando as leis das Ciências Naturais; necessário se torna ver a doença como processo social" [1].

A análise global do material resultou na sistematização das noções, que foram então agrupadas em dois grandes blocos: o contraponto social-biológico e a complexidade e diversidade do biológico.

\section{O contraponto social-biológico}

Aqui as referências ao biológico e ao social emergem como categorias opostas, quase auto-excludentes, ou mesmo de negação. Refletem concepções rigidamente disciplinares ou simplificadoras dos substratos constitutivos dos conceitos em questão.

A determinação social do processo saúde-doença revela um primeiro contraponto entre as categorias. Nos textos em que há referências a essa determinação, predominam concepções do biológico como depositário do social, ou seja, são as “coisas sociais" que explicam as naturais, como se sociedade e natureza pertencessem a universos diferentes, não constitutivos de uma única totalidade, constante e mútua relação, interação. Este contraponto se apóia no social para explicar os fenômenos de saúde-doença, em essência, e também intrinsecamente, biologicamente determinados, ou "naturalmente" constituídos. "A tentativa de construir e incorporar uma ecologia humana é sinal de que mais do que trabalhar com um conceito biológico mais abrangente, como preten- 
deu Theobald Smith, o modelo da história natural representava uma tentativa de dar conta do social, considerado como categoria importante na determinação das doenças, mas sem expor nem revelar suas dimensões políticas" [6].

Outro aspecto que a análise evidenciou é que o social é compreendido, em larga medida, através, e predominantemente, das categorias socioeconômicas e políticas: a distribuição desigual da riqueza e inserção socioeconômica; o modelo econômico do país; a relação e o domínio de classes sociais e suas dimensões políticoestatais; os movimentos sociais em saúde. Há, em certa medida, um entrincheiramento do conceito de social, o que o torna imobilizador, enrijecendo as possibilidades de se olhar a determinação social. É categórica a definição sobre o objeto de trabalho da Epidemiologia: são "processos de domínio social geral ou nas classes e grupos sociais particulares" [18]. A ancoragem em algumas categorias sociopolíticas - classe social, Estado, inserção socioeconômica etc. - revela claramente o que se compreende e o que se valoriza desse social, de que social se trata, de que social deve tratar a Epidemiologia.

Esta concepção interfere de tal forma no pensamento do que seja o biológico ou o social que chega a resultar numa dissociação artificial, como o demonstra a seguinte afirmação: “(...) cabe perguntar se esta sofisticação tecnológica crescente da pesquisa biomédica não irá contribuir para o desprestígio da saúde coletiva, ao provocar uma possível descaracterização ou desvalorização da natureza social vis a vis uma ênfase na natureza biológica dos processos que cercam a saúde e a doença" [31]. Há uma compreensão, evidente, de que a pesquisa e/ou práticas biomédicas estariam desvinculadas da esfera social ao dar "ênfase à natureza biológica dos processos", o que parece ignorar o fato de que este tipo de conhecimento ou prática da Saúde está socialmente “determinado", uma vez que expressa concepções hoje hegemônicas do que seja a doença, e que formas devem ser adotadas para a cura ou a reparação. Outro exemplo da determinação social do processo saúde-doença, em que as "coisas da sociedade" se sobrepujam às "coisas da natureza”, são as indicações de como proceder em uma análise epidemiológica: “(...) como um caminho necessário, a construção de referencial baseado nas formas concretas de inserção socioeconômica (condições de trabalho e condições de vida) da população, relevantes para explicar sua distribuição entre diferentes riscos de morbimortalidade a que está exposta” [14].

Outra noção do pensamento epidemiológico é identificar o biológico com o atributo individual. É como se as coisas coletivas fossem necessariamente da esfera do social e as do indivíduo, necessariamente, da esfera biológica. Ainda que se saiba que atributos individuais e biológicos não são propriamente sinônimos, na maioria dos trabalhos essas categorias aparecem autoreferidas. Predomina a concepção de que a determinação do processo saúde-doença é sempre social, coletiva; e o biológico é sempre particular, individual, clínico. "Posto desta forma, torna-se possível visualizar com mais clareza a especi-ficidade dos diferentes campos técnicos (a Clínica e a Epidemiologia), o que evidentemente implica reconhecer suas intercessões e objetivos comuns: reiterando, a saúde das populações. Isto permite repor a questão do individual e do coletivo nos seus devidos espaços, bem como identificar o caráter mais biológico ou mais social de cada uma das disciplinas" [30]. A não rediscussão dos referenciais teórico-epistemológicos que iluminam essas duas categorias faz com que não se explicite, clara e exatamente, de que biológico e individual se fala, e em conseqüência, quais são os atributos específicos de cada uma dessas categorias, quais são suas inter-relações: "A afirmação de uma epidemiologia de base biológica - através de movimentos denominados de epidemiologia clínica, ou mesmo epidemiologia molecular - implica o distanciamento da noção de coletivo” [24]. 
Cabe lembrar que fenômenos coletivos são também biológicos, como o demonstra, por exemplo, o estudo das espécies ${ }^{30}$.

Essa confusão entre individual e coletivo, e biológico e social, não corresponde propriamente às oposições clássicas em Ciências Sociais, que são entre individual e coletivo, e comunidade e sociedade, e não entre individual e social. A Sociologia e as outras ciências sociais constituem-se num momento histórico em que ganham conformação as categorias de cidadão, de sociedade civil, em que emerge a dinâmica urbano-industrial e as nações. Neste contexto, indivíduo e sociedade complementam-se como categorias explicativas históricas. A idéia de um sujeito que não é individual, mas coletivo, aparece nas análises de Marx e seus seguidores ${ }^{31}$. Esse ponto de vista de um sujeito total, um sujeito não individualizado, aparece na categoria de classe social, que o representa. Esse sujeito coletivo, como categoria de representação, é bastante adequado quando se trata de estudar grupos em condições específicas de vida e/ou de trabalho; sendo assim, seria mais adequado esclarecer que é a esse sujeito coletivo que a Epidemiologia se refere e evitar a contraposição indivíduo $\mathrm{x}$ sociedade.

A noção de biológico como depositário de objetividade, aparece, principalmente, nas discussões de caráter metodológico na Epidemiologia: "Esta tendência, que se intensifica com o desenvolvimento metodológico, dirige-se em boa parte para o entendimento de mecanismos subjacentes à expressão de uma patologia, enfatizando modelos explicativos de caráter biológico e ampliando a já excessiva fragmentação do conhecimento sobre a Epidemiologia dos principais problemas de saúde da população” [8]. Entretanto, deve-se lembrar que teoria e método constituem um constructo e, sendo assim, a objetividade do biológico revela que tipo de abordagem teórica se faz do objeto epidemiológico $^{32}$.

Muitos textos criticam de forma contumaz o conceito de objetividade, vincu- lando-o à idéia de fragmentação do objeto, de relações funcionais de causa/efeito, e à simples contabilização dos eventos de morbimortalidade. As críticas ao que se atribui de objetividade do biológico, ou seja à quantificação, são quase consensuais nos autores que a discutem, resultando numa 'quase' analogia entre biológico, quantificação e objetividade: "Uma análise, embora superficial, nos mostra que estas necessidades (de saúde), baseadas em critérios puramente biológicos e na medida que respondem à lógica de produção de serviços, dão prioridades a perspectivas contábeis nas suas múltiplas expressões. Mais uma vez pode-se registrar o desafio que se coloca para a Epidemiologia, qual seja o de reconstruir estes diagnósticos (...), mas incluir as características específicas dos conjuntos sociais e suas relações institucionais, ressaltando desta forma todos os elementos das condições de vida e de trabalho" [12]. O objetivo aparece, então, como característica instituinte, intrínseca, do biológico.

O biológico “objetivo", segundo a Epidemiologia, é aquele que se encontra dentro dos referenciais teóricos do funcionalismo, pois possibilita trabalhar o objeto epidemiológico em seus elementos segmentados - os agentes etiológicos e os hospedeiros, por exemplo -; em suas funções lineares - o ambiente externo hostil , carregado de potenciais microorganismos invasores deletérios; em suas relações excludentes - o normal e o patológico -; e, sobretudo, em abordagens bioestatísticas.

Por fim, no que se refere ao contra-ponto biológico-social, emerge a noção de ambiente. A questão ambiental, em sua feição contemporânea, vai recolocar, reinstituir a relação homem-natureza, provocando um reposicionamento dos saberes instituídos; tanto aqueles das ciências naturais - no caso, os das ciências biológicas - quanto o das ciências humanas - no caso, as sociais. Como as ciências naturais e as sociais se constituíram com bases em divisas artificiais entre os seres humanos e a natureza, entre mundo social e mundo 
natural $^{33,34}$, seus objetos serão postos em cheque com a emergência da crise/questão ambiental atual, seja em suas definições stricto sensu ou em seus formatos institucionalizados, seja, ainda, em seu arcabouço teórico original. Nesse sentido, pensar o biológico e o social tendo por referencia as questões relativas à problemática ambiental contemporânea implica olhar diferentemente, e a partir de novos enfoques, o homem e o mundo natural.

$\mathrm{Na}$ Epidemiologia as noções de biologia e ambiente aparecem, entretanto e ainda, de forma disciplinarizada, como categorias em certa medida dissociadas: “ $O$ estudo de causas e determinantes de doenças, uma questão posta como central à produção de conhecimentos em Epidemiologia, coloca esta no papel de sintetizadora dos conhecimentos em ciências biológicas, em ciências do ambiente e sociais" [8] ou "Resta-nos implementar uma estratégia de enfrentamento do problema (a respeito da epidemia de dengue), que não seja apenas fundamentada em ações sobre sua base biológica, mas sim sobre sua base socioambiental e cultural" [48]. Os trechos revelam um biológico desvinculado do ambiental, que por sua vez assume relevância através das categorias de sociedade e cultura. É como se a biologia, por meio do ambiente - categoria superior -, pudesse enfim ser alçada ao social.

O contraponto biológico-social revela o predomínio, no discurso epidemiológico, da construção teórica da 'determinação social da doença'. Esta formulação, ao reconhecer o social como a esfera de realização do humano e, portanto, da saúde das populações, explicita o que é o substrato da vida: o homem como ser essencialmente cultural, social. Entretanto, ao permanecer atinente às disciplinas sociais, tal como instituídas, no século $\mathrm{XIX}^{35}$, acaba por reduzir essa explicação apenas a algumas de suas categorias dessas disciplinas, restringindo o pensamento do que se compreende por esse social e, conseqüentemente, expulsando o biológico, socialmente construído.

\section{Complexidade e diversidade do biológico}

Não há na Epidemiologia uma construção do objeto epidemiológico a partir da concepção da complexidade do biológico. Ainda que a questão da complexidade tenha sido, em algum momento, abordada pela Epidemiologia, ela não constituiu, no período em estudo, um de seus objetos centrais. Apenas no terceiro Congresso Brasileiro, em 1995, uma abordagem mais sistemática e consistente do biológico com bases na categoria do "complexo" aparece, revelando que a idéia de complexidade como atributo do fenômeno biológico parece estar, ainda, em constituição.

Há a percepção sobre a necessária revisão do objeto epidemiológico incorporando outras dimensões em sua constituição, determinação; “(..) pensar uma epidemiologia que transcenda as fronteiras das propostas investigativas habituais significa, preliminarmente, cogitar formas de abordagem de interfaces em que ocorrem relações recíprocas entre instâncias diferentes e complexas que não podem mais ser concebidas separadamente, localmente. Em outras palavras, implica a necessidade de mediação simultânea entre local/ global e natural/social" [38]. Essa inquietação se revela também quanto à discussão metodológica: "Esta valorização da técnica per se, estimulada pela rápida incorporação de novos métodos quantitativos, tem estimulado o uso acrítico deste novo instrumental, que permite o tratamento simultâneo e discriminado de ampla gama de variáveis, freqüentemente, desvinculadas de sua dimensão biológica e de sua inserção social" [14].

Há o reconhecimento (e o incômodo) com o fato - real e empiricamente observável - de que biológico e social constituem constructu cujas fronteiras estão cada vez mais difusas. O esgarçamento dessa fronteira propõe aos profissionais do campo novos problemas teóricos e metodológicos que lhes permitam captar a complexidade do real: "Qualquer análise ancorada nas 
políticas de transformação da situação de vida e saúde das populações requer conceitos e métodos caracterizados pela diversidade de sua extração, para que possibilitem a compreensão da complexidade dos sistemas dinâmicos biológicos e históricos (...)" [34].

Há incursões bastante consistentes na direção da incorporação de "novos" conceitos - sejam eles advindos da Biologia, da Ecologia, ou mesmo das Ciências Sociais. Começam a integrar os estudos epidemiológicos categorias até então ausentes desse discurso, como a interação, o tempo, as dimensões da história em biologia; a evolução, a diversidade, o espaço. "No caso dos fenômenos biológicos estudados pela epidemiologia, as condições iniciais da experiência não retornam. O tempo é irreversível e unidirecional. Sendo assim, o que significaria contextualizar temporalmente um estudo epidemiológico? Não implicaria também trabalhar a dimensão do tempo como história? Sem dúvida, mesmo no contexto da biologia, as transformações evolutivas vão de encontro à crença de invariabilidade, fixidez e universalidade dos seres vivos" [35]. Há, portanto, cada vez mais a preocupação com o tempo histórico, tempo biológico, ainda que em formulações preliminares.

Outra categoria das ciências humanas que aparece revisitada é o espaço, agora numa leitura contemporânea da Geografia. Incorpora-se, para além do espaço cartográfico, a noção de território, numa acepção social ${ }^{36,37}$. "Uma vertente que vem sendo desenvolvida na América Latina é a da análise das condições de saúde de populações referenciadas territorialmente. Embora tão antiga quanto a Epidemiologia, a abordagem do espaço passa agora a ser empreendida numa concepção não só da dimensão ecológica, natural ou administrativa, mas do espaço social e historicamente constituído, como expressão de transformações sociais específicas de ocupação" [31].

A diversidade é outra categoria que vai emergindo, gradativamente, nesse discur- so. Os textos ainda não se dedicam ao tema da diversidade a ponto de extrair desta categoria todo o seu potencial analítico, mas já há o reconhecimento de que os fenômenos em saúde-doença, ainda que aparentemente únicos, integrais, totais, contêm grande diversidade biológica intrínseca, e não apenas extrínseca: " $A$ diversidade $d o$ HIV-1 está em torno de 6\% num mesmo indivíduo, podendo chegar a 50\% entre indivíduos de diferentes regiões geográficas. Com essa alta taxa de variação, é de se esperar que o vírus apresente características biológicas diferentes. (...) São necessários estudos para determinar como se comportam os diversos subtipos em relação à evolução clínica, transmissibilidade e resposta imunológica. É também possível que vírus de um mesmo subtipo tenham características diferentes" [44].

A diversidade não é, nesse sentido, patrimônio apenas das culturas, das sociedades humanas e das espécies, mas é também infraespecífica, existindo internamente aos organismos ${ }^{38}$. Essa diversidade biológica interfere, determina e condiciona práticas sociais (o comportamento da doença nos indivíduos, os tratamentos a serem ministrados, as políticas públicas no controle e prevenção de doenças etc.), bem como práticas socioecológicas - no caso, as que interferem no desenvolvimento dos agentes etiológicos. "Apesar dos esforços para controlar a cólera com ações de bloqueio, melhoras focais das ações de saúde pública e campanhas de vacinação maciças, ela tem se mantido (...) Em 1961, uma nova pandemia de cólera começou nas Ilhas Celebes, causada por uma nova cepa de V. cholerae 01, biótipo El Tor. (...) $O$ ressurgimento da cólera deu um sentido renovado às questões de saúde pública..." [22].

\section{Discussão}

Como se vê, a Epidemiologia vem trabalhando com diferentes - e divergentes concepções do que seja biológico, do que seja social. A análise dos Congressos de- 
monstrou, entretanto, que predominaram ao longo desses dez anos de produção concepções ainda simplificadoras dessa relação, dessa interação, mediante a extrema complexidade envolvida nesses conceitos.

Essas formulações acabam ofuscando outras proposições do próprio campo epidemiológico, extremamente ricas e pertinentes, e que, na maioria das vezes, ficaram secundadas ou foram dissolvidas. É o caso da pergunta perspicaz sobre a relação sociedade-natureza e o objeto da epidemiologia: "Qual a concepção de natureza que a epidemiologia traduz? A ciência moderna funda-se na perspectiva de controlar e instrumentalizar a natureza. Provoca uma ruptura entre homem e natureza, 'naturalizando-a', isto é, percebendo-a como um objeto inerte. Esta concepção de natural impregna também as ciências da vida e, conseqüentemente, o próprio homem na sua dimensão biológica” [27]. Reconhecendo a dimensão sociohistórica dos processos saúde-doença, a pergunta situa aí o questionamento sobre a determinação social; ou seja, de que dimensão biológica, socialmente construída, se fala? Com que conceito de natureza, construído tanto pelas ciências humanas quanto pelas ciências naturais, se tem trabalhado?

A riqueza das problematizações encontradas no material analisado demonstra o grau de perplexidade, e perspicácia, com que o campo se defronta. A complexidade do quadro nosológico parece ser um dos estopins dessa avalanche de questionamentos. " $O$ que se pretendeu nessa colocação 'Uma Nova Transição?' foi tão somente chamar a atenção para o fato de que, mesmo tendo ultrapassado a transição epidemiológica, a estrutura da mortalidade por causas não é fixa, isto é, não é estável, estando sujeita a mudanças. Entre essas, não somente mudanças de posição no ranking entre cardiovasculares e as neoplasias malignas, mas - e principalmente - que as doenças infecciosas ('novas' e 'antigas') podem surgir ou ressurgir e voltar a assumir papel de destaque entre as causas de morte" [7]. Essa "nova transição” (também denominada de reemergência e/o recrudescência de doenças) ${ }^{39}$, parece ser um dos fatores desencadeantes de novas problematizações na Epidemiologia. Nessa transição, surgem e se desdobram, de maneira inesperada e imprevisível, vários dos fenômenos já conhecidos, além de outros inusitados. A emergência da AIDS, e a maior virulência da dengue por exemplo, encaixam-se em larga medida nesses processos,como fenômenos de natureza biosocial que são.

"Ora, além dos altos índices em que aquelas doenças (referência à malária, dengue, febre amarela etc.) ocorrem insistentemente em nosso meio, novas entidades surgem com características nitidamente infecciosas. É o caso da AIDS e da infecção hospitalar. Para além do debate sobre tipologia e/ou nomenclatura classificatória, são entidades mórbidas complexas, envolvendo uma multipicidade interrelacionada de fatores e elementos $e$ que surgem em quadro estrutural igualmente complexo, dentro do qual se explica a ocorrência de doenças" [12].

Uma proposição teórico-metodológica é, então, sugerida: "Se o social age no cultural e este no biológico, o estudo deste envolverá um caminho inverso, isto é, estudar os aspectos culturais e sociais que se manifestam no campo biológico" [18]. Esta colocação abre espaço, claramente, para se pensar as "coisas da sociedade" dentro das "coisas da natureza”, e vice-versa. Abre caminhos para se pensar a determinação sociobiológica das diferentes naturezas.

Biológico é atributo de seres orgânicos, vivos, coletivos e individuais. Sendo assim, biológico e social não configuram uma contraposição, diferentemente, por exemplo, das oposições clássicas encontradas no campo das ciências sociais, como aquela entre individual e coletivo, natureza e cultura $^{40}$. O biológico é social, seja na esfera dos seres individuais ou dos seres em comunidades, coletividades, populações. Portanto, torna-se necessário desenvolver esforços no sentido de trabalhar (por den- 
tro do objeto epidemiológico) essas interações, essas relações, aprofundando o diálogo interdisciplinar, epistemológico ${ }^{41}$, menos como delimitação de territórios de saberes disciplinarmente disciplinados, e mais como processos e interações como de fato o são.

A relação entre o conceito de objetividade biológica e matriz positivista do pensamento parece estar bem esclarecida. Essa crítica tem bases epistemológicas bastante sólidas no campo da própria Epidemiologia, tendo por referência a produção de Canguilhem ${ }^{5,42}$. É sabido que a corrente funcionalista, de matriz Durkheimiana nas ciências sociais, utilizando-se do conceito de anomalia, por exemplo, serve muito à lógica da normalidade objetiva da biomedicina, "o normal como o mais freqüente (p. 237)" 42 . E a objetividade como resultado do mais freqüente.

Não são consideradas, entretanto, outras possibilidades teórico-metodológicas de compreensão da objetividade do biológico. O pensamento epidemiológico não se remete, em momento algum, a dimensões próprias ao campo disciplinar da Biologia no qual convivem - e polemizam diferentes correntes, como a da biologia funcional e a evolutiva, por exemplo, segundo classificação de Mayer ${ }^{43}$, e que trabalham diferentemente com o princípio da objetividade.

O conforto obtido com a fetichização da categoria de meio-ambiente permite contemplar a relação biológico-social passando ao largo da necessária re-discussão desses conceitos, teorias e concepções ${ }^{44}$. Muitas vezes, no pensamento epidemiológico, o ambiente aparece reafirmando a idéia de meio, similar a exterior, a lugar, ao contexto que abarca o biológico e o social. Em certo sentido, um conceito de ambiente refém da idéia de meio do Preventivismo, agora sob nova roupagem.

A questão ambiental, em pauta desde meados do século XX, tem a ver com a crise de recursos naturais em escala planetária, criando as bases do movimento ambientalista que vai estruturar sua ação na perspectiva da preservação do planeta tendo em vista as futuras gerações. Parte da premissa de que a civilização contemporânea exaure os recursos e inviabiliza a vida, tornando-se insustentável a médio e longo prazo $^{45}$. Desta forma, o pensamento ambientalista vai pôr em causa as relações sociais em si e de apropriação da natureza.

As ciências humanas, e nelas as sociais, se consolidam no século XIX numa intensa luta com as ciências naturais sobre quem iria controlar o conhecimento relativo ao humano. Nessa medida, ficaram reféns de sua "culturalização" ${ }^{33,34,46}$. O esforço em construir um campo de saber relativo ao humano levou as ciências humanas a desconsiderar o natural, cada vez mais compreendido, apenas, como objeto de apropriação e uso ou reduzido a meio condicionante/determinante de certas realidades socioeconômicas, culturais. A natureza foi totalmente desvinculada dos homens, que dela se proviam. Assim, ciências naturais e humanas, biologia e ciências sociais (independentemente de seu arcabouço teórico - funcionalista, materialista, fenomenológico), foram construindo e reafirmando, no decorrer de sua institucionalização disciplinar, o divórcio entre sociedade e natureza; contribuindo para a cristalização da idéia de natureza como um bem para o usufruto e apropriação. As Ciências Sociais não realizaram um debate epistemológico sobre a Natureza, que foi incorporada principalmente como recurso produtivo. Constituídas simultaneamente à emergência e desenvolvimento do Mundo Moderno, urbano-industrial, as Ciências Sociais ocuparam-se da questão social que irrompia no horizonte dessas sociedades, secundando o debate sobre o natural. Na Sociologia, por exemplo, a relação do homem com a natureza permanece um pressuposto da explicação, porém não como valor analítico, e muito menos como valor explicativo dos fenôme$\operatorname{nos}^{46}$. A vida, como fenômeno da natureza, não foi nunca objeto epistemológico dessas ciências; pelo contrário, na medi- 
da em que no século XIX, momento de sua constituição, as ciências sociais buscaram traduzir para o campo da sociedade, da cultura e da história os procedimentos que haviam sido elaborados e continuavam a ser elaborados nas ciências físicas e naturais - ou seja, quando elas se propõem o projeto de legitimação do status de ciência -, relegaram àquelas o patrimônio da discussão do processo vital, das "coisas vivas”, mantendo para si o ocupar-se das “coisas sociais" ${ }^{33}$. A luta epistemológica por aquilo que se considerava ser o conhecimento legítimo já não era uma luta para saber quem havia de controlar o conhecimento relativo à natureza (já que os cientistas naturais haviam claramente adquirido direitos exclusivos sobre este domínio por volta do século XVIII), mas antes uma luta para estabelecer quem iria controlar o conhecimento relativo ao mundo humano ${ }^{35,47}$. É neste constructo que a Epidemiologia vai encontrar as bases teórico-conceituais, epistemológicas, para a elaboração da sua determinação social. Não é de surpreender, portanto, que ela se renda a essa construção, historicamente determinada.

Até mesmo a Ecologia, ciência que se constitui contemporaneamente às Ciências Sociais (o vocábulo oekologie foi formulado em 1866 por Ernest Haeckel) ${ }^{48}$, se desenvolveu durante longo período sem incorporar em seu arcabouço teórico-conceitual a sociedade humana. Na sua gênese, a Ecologia preocupa-se com os seres não humanos e, mesmo tendo contribuído no campo das ciências naturais, especialmente as biológicas, para uma compreensão dos fenômenos da natureza como processos de interrelação, evolução, interação, interdependência etc., não incorporou a espécie humana no seu objeto de estudo, desvinculando-a da natureza.

As ciências, fragmentadas no século XIX, fragmentaram com elas o homem e o mundo - social e natural. Das humanidades, a ciência que talvez tenha preservado de forma mais perene um patrimônio que articula homem/natureza foi a Antropolo- gia dos estudos etnográficos. Das ciências naturais, apenas a teoria evolutiva ${ }^{43,49}$ contemplou, de soslaio, a espécie humana.

\section{Conclusão}

Na tentativa da construção do social na Epidemiologia, desenvolveu-se uma vastíssima discussão sobre a Saúde e sua "sombra", a Doença, em sua manifestação biológica. Nesse construto, o biológico adquire uma especificidade de fenômeno mínimo ao qual se pode aplicar a noção de "biologicismo", segundo Mendes Gonçalves $^{50}$. O grande impasse parece ser, então, reposicionar esse marco, recolocar a questão sobre o quê a Epidemiologia entende por biológico e o quê compreende por social; a quais disciplinas, a que marcos teóricos recorre ou refere quando trabalha com um ou outro conceito. O campo da Saúde Pública/Coletiva, e nele a Epidemiologia, está impregnado desse construto. Nele, o processo vital é desmembrado em social e biológico, em individual e coletivo, e assim por diante. Rompe-se o todo. A Epidemiologia encontra no social “societário", em oposição a um biológico 'biologicista', a explicação do processo saúde-doença.

"Embora as digressões sobre a interface entre o biológico e o social não ocupem hoje um lugar de destaque dentro das ciências sociais, o debate permanece ativo dentro da Epidemiologia, principalmente, quando vem à tona a sua relação com a Clínica. É como se a Epidemiologia, assim como as personagens da tragédia grega, tivesse que expiar para sempre uma culpa por perquirir um objeto que contém o biológico em sua constituição (p. 9)" ${ }^{51}$.

Essa “duplicação” na Epidemiologia encontra nas Ciências Sociais e Naturais, mais especificamente as Biológicas, sua justificação. A idéia de um "sujeito coletivo” veio acrescentar à Epidemiologia qualidade à população, objeto dos estudos epidemiológicos. Mendes Gonçalves ${ }^{50}$, ao 
analisar as Epidemiologias Ecológica e Social, aponta uma possibilidade real e profícua de interlocução entre ambas:

“Afinal, é possível identificar um discurso que não mais se refere apenas à distribuição e às causas da distribuição das doenças nos homens, mas fala da espécie humana - não uma somatória de indivíduos, mas uma entidade com individualidade própria - e considera suas doenças como decorrência do convívio dessa espécie com outras e com o meio, e da forma pela qual essa espécie se organiza para esse convívio. (...) A doença não é mais, enquanto objeto conceitual primeiro, enquanto dimensão do real depois, uma característica do homem, mas da espécie (p. 76-77)”.

Essa concepção acrescentaria, para além da "determinação social dos processos saúde-doença”, outros elementos que ampliariam essa determinação, tornando o objeto da epidemiologia mais complexo, mais próximo dos fenômenos reais, porque mais diverso, dinâmico, histórico, em evolução, simultaneamente natural e social $^{49,52}$.

A amplitude de conhecimentos sobre o processo saúde-doença, que agora transita do âmbito socioglobal ao molecular, coloca à Epidemiologia o desafio de trabalhar com referenciais teóricos que contemplem essa complexidade, diversidade. A ecologia política ${ }^{44}$, circunstanciada pela problemática ambiental contemporânea, abre novas possibilidades de compreensão dos diferentes níveis dos fenômenos biológicos, dos indivíduos às populações, dos seres complexos às moléculas, e fornece um arsenal conceitual que contribui, e muito, para os atuais desafios postos ao campo da Saúde Coletiva.

\section{Referências}

1. Canesqui AM. Ciências Sociais e Saúde no ensino médico. In: Canesqui AM (Org.) Ciências Sociais e Saúde para o Ensino Médico. São Paulo: Editora Hucitec/ Fapesp; 2000. p. 25-46.

2. Camargo Jr KR de. Biomedicina, Saber \& Ciência: uma Abordagem Crítica. São Paulo: Editora Hucitec; 2003.

3. Marsiglia RG, Spinelli SP. As Ciências Sociais em saúde e o ensino. In: Canesqui AM (Org.) Dilemas e Desafios das Ciências Sociais na Saúde Coletiva. São Paulo: Editora Hucitec/Abrasco, 1995. p. 123-32.

4. Stotz EN. A Saúde Coletiva como projeto científico: teoria, problemas e valores na crise da modernidade. In: Canesqui AM (Org.) Ciências Sociais e Saúde. São Paulo: Editora Hucitec/Abrasco, 1997. p. 273-84.

5. Arouca S. O Dilema Preventivista. Contribuição para a compreensão e crítica da Medicina Preventiva. São Paulo, Rio de Janeiro: Editoras Unesp/Fiocruz; 2003.

6. Costa N do R. Ciências Sociais e Saúde: considerações sobre o nascimento do campo da Saúde Coletiva no Brasil. Saúde em Debate 1992; 36: 58-65.

7. FGV/Fundação Getúlio Vargas e MEC/Fundação Assistência ao Estudante. Dicionário de Ciências Sociais. Verbete: funcionalismo. Rio de Janeiro; 1986. p. 503.
8. Barreto ML. A Epidemiologia, sua história e crises: notas para pensar o futuro. In Costa DC (Org.) Epidemiologia: Teoria e Objeto. São Paulo: Editora Hucitec-Abrasco, 1990. p. 19-38.

9. Escorel S. Reviravolta na Saúde. Origem e Articulação do Movimento Sanitário. Rio de Janeiro: Editora Fiocruz; 1999.

10. Teixeira CF. Epidemiologia e Planejamento em Saúde. Contribuição ao Estudo da Prática Epidemiológica no Brasil 1990-1995 [tese de doutorado]. Salvador: Instituto de Ciências Sociais da UFBA; 1996.

11. Bordieu P. O campo científico. In Ortiz R (Org.). Pierre Bordieu. São Paulo: Ática Editora; 1983. [FALTA INSERIR NÚMERO DAS PÁGINAS]

12. Barros MAB. Epidemiologia e Superação das Iniqüidades em Saúde. In: Barata RB, Barreto ML, Almeida Filho N de, Veras RP (Orgs.). Eqüidade e Saúde: Contribuições da Epidemiologia. Rio de Janeiro: Editora Fiocruz/Abrasco; 1997. Série Epidemiológica 1: 161-76.

13. Romero A. El Desarollo Histórico de la Epidemiologia en América Latina. In: I Congresso Brasileiro de Epidemiologia. Campinas, 1990. Anais. Campinas: Abrasco; 1990. p. 81-107. 
14. Silva GR da. Avaliação e Perspectivas da Epidemiologia no Brasil. In: I Congresso Brasileiro de Epidemiologia. Campinas, 1990. Anais. Campinas: Abrasco; 1990. p. 108 39.

15. Pereira JC. Medicina, Saúde e Sociedade. Estudos de Saúde Coletiva 1986; 4: 29-37.

16. Loureiro S. Brasil: Desigualdade Social, Doença e Morte. In: I Congresso Brasileiro de Epidemiologia. Campinas, 1990. Anais. Campinas: Abrasco; 1990. p. 63-80.

17. Almeida Filho N de. O Problema do Objeto de Conhecimento na Epidemiologia. In: Costa DC (Org.). Epidemiologia. Teoria e Objeto. São Paulo: Editora Hucitec/Abrasco; 1990. p. 203-20.

18. Ayres JRCM. Epidemiologia e Emancipação. São PauloRio de Janeiro: Editora Hucitec/Abrasco; 1995.

19. Ayres JRCM. Sobre o Risco. Para Compreender a Epidemiologia. São Paulo: Editora Hucitec; 1997.

20. Nunes ED. Sobre a Sociologia da Saúde. São Paulo: Editora Hucitec; 1999.

21. Canesqui AM. Introdução: Os Novos Rumos das Ciências Sociais e Saúde. In: Canesqui AM (Org.). Ciências Sociais e Saúde. São Paulo: Editora Hucitec/Abrasco; 1995. p. 1935.

22. Mann PH. Métodos de Investigação Sociológica. Rio de Janeiro: Zahar Editores; 1970.

23. Minayo MCS. Hermenêutica-Dialética como Caminho do Pensamento Social. In: Minayo MCS, Deslandes SF (Orgs.). Caminhos do Pensamento. Epistemologia e Método. Rio de Janeiro: Editora Fiocruz; 2002. p. 83-107.

24. Vieira MPA, Peixoto MCR, Khoury YMA. A Pesquisa em História. São Paulo: Editora Ática; 1998.

25. Goldmann L. Dialética e Cultura. Rio de Janeiro: Editora Paz e Terra; 1967.

26. Minayo MCS. O Desafio do Conhecimento. Pesquisa Qualitativa em Saúde. São Paulo-Rio de Janeiro: Editora Hucitec/Abrasco; 1994.

27. Quivy R, Campenhoudt LV. Manual de Investigação em Ciências Sociais. Lisboa: Gradiva; 1998.

28. Boudon R, Lazarsfeld P. Le Vocabulaire des Sciences Sociales. Paris: Mouton et Cie; 1967, cit. in Hirano S. Projeto de Estudo e Plano de Pesquisa. Hirano S.. (Org.). Pesquisa Social. Projeto e Planejamento. São Paulo: T. A. Queiroz Editor; 1979. p. 89-110.

29. Barata RB. Epidemiologia Social. Rev Bras Epidemiol 2005; 8(1): 7-17.

30. Mayer E. This is Biology. The Science of the Living World. Cambridge-London: The Belknap Press of Harvard University Press; 1997.
31. Luckács G. Rosa Luxemburgo Marxista. In: Luckács G. História e Consciência de Classe. Lisboa: Publicações Escorpião; 1974. p. 41-58.

32. Robert Moraes AC. Meio Ambiente e Ciências Humanas. São Paulo: Editora Hucitec; 1994

33. Comissão Gulbenkian para a Reestruturação das Ciências Sociais. Para Abrir as Ciências Sociais. São Paulo: Cortez Editora; 1996.

34. Geertz C. O Estranho Estranhamento: Charles Taylor e as Ciências Naturais. In: Geertz C. Nova Luz sobre a Antropologia. Rio de Janeiro: Jorge Zahar Editor; 2001. p.131-42.

35. Luz MT. Novas Realidades em Saúde, Novos Objetos em Ciências Sociais: Tendências Teórico-Conceituais. In: I Congresso Brasileiro de Ciências Sociais e Saúde (resumo da comunicação para Mesa Redonda, mimeo). Curitiba: Abrasco/Nesco/SES PR; 1995.

36. Santos M. Espaço e Método. São Paulo: Nobel Editora; 1992.

37. Najar AL, Marques EC. A Sociologia urbana, os modelos de análise da metrópole e a Saúde Coletiva: uma contribuição para o caso brasileiro. Ciência \& Saúde Coletiva 2003; 8(3): 703-12.

38. Rensch B. Evolution Above The Species Level. New York: Science Editions; 1956.

39. Barreto ML. Emergência e "Permanescência" das Doenças Infecciosas. Médicos Julho/Agosto 1998: 17-24.

40. Corcuff P. As Novas Sociologias - Construções da Realidade Social. Bauru: Edusc; 2001.

41. Minayo MC de S, Assis SG de, Deslandes SF, SOUZA ER de. Possibilidades e dificuldades nas relações entre ciências sociais e epidemiologia. Ciência \& Saúde Coletiva 2006; 8(1): 97-107.

42. Canguilhem G. O Normal e o Patológico. Rio de Janeiro: Forense Universitária; 1990.

43. Mayer E. Causa y efecto en biologia. In: Martinez S, Barahona A (Comp.) Historia y Explicación em Biologia. México: Fondo de Cultura Económica-Ediciones Científicas Universitárias; 1998. p. 82-95.

44. Latour B. Políticas da Natureza. Como fazer ciência na democracia. Bauru: Edusc; 2004.

45. Ferreira LC. Questão Ambiental. Sustentabilidade e Políticas Públicas no Brasil. São Paulo: Boitempo Editorial; 1998.

46. Giuliani GM. Sociologia e Ecologia: um Diálogo Reconstruído. Raízes. Revista de Ciências Sociais e Econômicas 1998; XVII(16): 25-40.

47. Thomas K. O Homem e o Mundo Natural. São Paulo: Companhia das Letras; 1996. 
48. Acot P. História da Ecologia. Rio de Janeiro: Editora Campus; 1990.

49. Lewontin RC. Biology as Ideology. The Doctrine of DNA. New York: Harper Collins Publishers; 1991.

50. Mendes Gonçalves RB. Reflexão sobre a Articulação entre a Investigação Epidemiológica e a Prática Médica a propósito das Doenças Crônico-Degenerativas. In: Costa DC (Org.). Epidemiologia: Teoria e Objeto. São Paulo: Editora Hucitec/Abrasco; 1990. p. 39-86.
51. Melo Filho DA. Contribuição à Compreensão Crítica da Epidemiologia Social [dissertação de mestrado].

Salvador: Universidade Federal da Bahia; 1994.

52. Latour B. Jamais fomos Modernos. São Paulo: Editora 34; 1994.

Recebido em: 18/05/07

Versão final reapresentada em: 01/10/07

Aprovado em: 09/11/07 